\title{
CAFÉ, DO COLONATO AO BÓIA-FRIA 1
}

\author{
YOSHIYA NAKAGAWARA2
}

NAKAGAWARA, Y. Café, do colonato ao bóia-fria. Semina: Ci. Soc./Hum., Londrina, v. 15, n. 3, p. 270-279, set. 1994.

AESUMO: O artigo traça uma visão geral das transformações verificadas na cafeicultura no território brasileiro, particularmente nos Estados de São Paulo e Paraná. Apresenta um estudo sobre as diferentes formas de relações sociais de trabalho e de produção, envolvendo a cafeicultura. Sintetiza o papel social e económico que o café representou para o Brasil.

PALAVRAS-CHAVE: Café; trabalhador rural; fronteira.

\section{1 - INTRODUÇĀo}

Na formação sócio-econômica do território brasileiro, a cafeicultura representou, como nenhum outro produto agrícola, um papel fundamental na sua ocupação, não só abrindo regiões de mata virgem em várias áreas de fronteiras de expansão pioneira, mas também pela sua repercussão social e política, no cenário nacional e internacional.

Desde a sua entrada no Brasil, em 1727, provocou a surgimento de uma série de atividades, tanto rurais como urbanas, contribuindo na abertura de novas opções econômicas, sendo a base da atividade industrial paulista.

A expansão da cafeicultura pelo território brasileiro. principalmente a partir do início do século passado, alastrando-se pelas regiöes fluminenses, paulistas e mineiras teve no Estado do Paraná, a partir da década de 1930, a sua última ảrea de expansão como um "locus" ótimo.

A cultura cafeeira modificou substancialmente o quadro agrário e urbano do Brasil, fazendo com que sur. gissem relações de trabalho especificas para atender a demanda crescente no mercado internacional. Criou também oportunidades de trabalho e de ascensão social para os imigrantes que vieram ao Brasil, complementando e melhorando a mäo-de-obra brasileira, pelo seu aspecto disciplinar, particularmente na área rural.

São transcorridos 263 anos de história do café no Brasil, repleta de fatos que mostram a sua significativa participação na economia brasileira. Neste ensaio pretende-se apresentar a sua importância na vida sócio-eco- nômica brasileira, e trazer reflexỏes sobre as principais transformações ocorridas nas relações de trabalho, envolvendo essa cultura.

\section{2 - O PERCURSO SOCIAL E ECONÔMICO}

A planta do café é originária da Eriópia na África sendo levada para a Arábia no século $X V$, depois, fol para o Cairo-Egito, e, em 1554, jå estava em Constantinopla. tornando-se os árabes, os primeiros exportadores de café (TAUNAY, 1945).

No Brasil, introduzido através do Pará região norte (1727) só era comercializado em farmácias, como uma bebida estimulante; foi depois levado ao Nordeste, e em 1760 , foi plantado no Rio de Janeiro, já como uma cultura comercial de expressăo econômica.

Hoje, hå vårias recomendaçöes tecnológicas disponiveis para se obter maior produtividade, quer se referin. do ao espaçamento mais adequado combate às pragas e doenças, indicações de variedades conforme as regiöes etc.

A cafeicultura brasileira está intimamente associada aos vărios fatores de expansão territorial, como: constru ção de ferrovias e rodovias, instalações de povoados, ci dades e implementação de infra-estruturas urbanas. Ain-

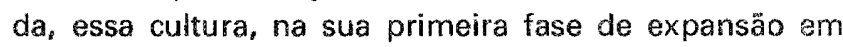
grandes fazendas paulistas, mineiras ou fluminenses esteve associada ao trabalho escravo dos negros e somente a partir do fim do século $X \mid X$ os imigrantes europeus e asiåticos compõem a mão-de-obra na cafeicultura.

1 - Este artigo é uma versäo resumida do artigo publicado em língua japonesa na Revista Rekishi to tiri (História e Geografia). Tókio, Japão, n. 420, p. 5-16. 1990, com o titulo original: "Cafeicultura Brasileira - Transformaçöes a Perspectivas". Este trabalho teve a colaboração de Paulo Henrique Maravieski Brambilla, acadêmico de Ciências Econômicas da Universidade Estadual de Londrina.

2 - Departamento de Geociências/CCE - Universidade Estadual de Londrina, Caixa Postal 6001, Londrina, Paraná, Brasil, CEP 86051-970. 
Podem ser feitas outras associações mais recentes, como a presença do "Bóia-Fria" na força de trabalho rural, cujo contingente é engrossado por ocasião da coIheita. O "Bóia-Fria" es o trabalhador volante, diarista, composto por homens, mulheres ou crianças que executam tarefas diárias, prestando serviços sem vínculo empregatício com o proprietário e residindo fora das propriedades.

Mas, a maior associação que se faz é a econômica. O café se desenvolveu como cultura de exportação, no interior de formações estruturais sócio-econômicas já existentes no Brasil, sob um modelo marcadamente mercantilista (CANCIAN, 1977), como continuidade à expansão comercial da Europa no Brasil. O elemento fundamental do sistema era a "grande propriedade monocultural trabalhada por escravos" (PRADO JUNIOR, 1965 apud CANCIAN, 1977), porém, em um novo quadro internacional, e numa conjuntura diferente daquela que havia gerado a economia açucareira do período colonial, que se desenvolveu no litoral nordestino do Brasil.

A irradiação do café para as fazendas paulistas e mineira, partindo da Baixada Fluminense, encontrou abundância de terras férteis e de baixo valor monetário, facilitando a grande migração e expansão do café para as regiões florestadas, sendo o Norte do Paraná, a sua última fronteira sul apta para a cafeicultura, dada a limitação climática principalmente. Uma outra associação, cujo fam tor influiu decisivamente nos rumos da cafeicultura bra. sileira, foi a geada, temida pelos cafeicultores pois, conforme a sua intensidade, chega a destruir o cafezal, prejudicando as colheitas futuras e causando prejulzos incalculáveis aos cafeicultores.

A seguir, veremos as caracteristicas e as transformações dessas associações, no tempo e nas várias regiōes brasileiras.

\section{3 - CAFÉ, EXPANDINDO FRONTEIRAS}

Antes do Brasil, a colônia francesa do Haiti (América Central) era a principal fornecedora mundial do café $e_{\text {. }}$ no mercado internacional, a cana-de-açúcar começa a declinar em importância, a partir do decênio 1831/40, pela intensificação da cultura da beterraba pelos europeus (PESSAMILIO, 1978). Cuba também concorria com o Brasil na produçäo de açúcar, abastecendo o mercado em expansão nos Estados Unidos, com fretes mais baixos e mão-de-obra abundante.

As exigências de infra-estrutura e investimentos não eram grandes, se comparadas ao fator terra, abundante e barata, na época da grande expansäo cafeeira, no século XIX, principalmente na região Centro-Sul do Brasil, promissora para o cultivo do cafe. O Vale do Paraíba (1825-1850) foi o ponto de partida para o Oeste Paulista, com centro em Campinas e estendendo-se até Ribeirão Preto, cujos solos eram mais férteis e topograficamente mais adequados que os do Vale do Parafba.

De 1860 a 1870 , foi o auge da cafeicultura fluminen se, mas as lavouras fluminenses se encontravam com os solos já esgotados pela extração contínua de nutrientes Semina Ci. Soc./Hum., v. 15, n. 3, p. 270-279 sem a reposição, e as riquezas que eram canalizadas para - Rio de Janeiro passaram a ser concentradas em São Paulo em busca do Porto de Santos. Em 1881 São Paulo já suplanta a produção de Minas Gerais e em 1889 já ultrapassa a produção cafeeira do Rio de Janeiro. Até 1872 o porto do Rio escoava $81 \%$ da produção cafeeira do Brasil, perdendo a primazia para o porto de Santos, em virtude da grande produção se concentrar nas férteis terras recém desbravadas do Estado de São Paulo.

No fim do século XIX havia ainda grandes extensões de terras cobertas de mata virgem, com baixa densidade demográfica e os interesses comerciais eram ainda controlados por Portugal e Holanda. O primeiro censo, realizado em 1872, acusou apenas 10.112.061 habitantes, dos quais 1.500 .000 eram escravos. A economia de subsistência era prática comum à época, juntamente com a cafeicultura. O progresso demográfico e econômico eram lentos, sendo dinamizados com a entrada de imigrantes, iniciada nessa época, de forma gradativa, atingindo o maior volume de contingente, de 1885 a 1904 quando entraram cerca de 1.200.000 imigrantes, sendo os italianos, a maioria.

As experiências com o trabalho livre na cafeicultura foram introduzidas por fazendeiros paulistas, na segunda metade do século XIX, para substituir ou suplementar o trabalho escravo, pois, a cafeicultura exigia muita mãode-obra e de forma intensiva durante todo o ano (STOLCKE, 1986). A escravidão só foi abolida em 1888, mas os cafeicultores paulistas já trabalhavam com a mão-deobra imigrante desde 1847.

\section{4 - MÄQ-DE-OBRA IMIGRANTE NA CAFEICULTURA}

A agricultura brasileira se intensificou com a vinda dos imigrantes da Europa e da Ásia, passando a se caracterizar como uma atividade empresarial que conferia riqueza, prestigio político e autoridade aos cafeicultores. Um grande fazendeiro paulista o coronel Schimidt, chamado "o Rei do Cafe" possuia 33 fazendas em Ribeirão Preto e Sertãozinho, com 8.000 colonos distribuidos em mais de 1.000 casas (STOLCKE, 1986).

A paisagem rural era um "mar ondulado" de ca" feeiros, e onde houvesse solo fértil o cafeicultor plantava café desde que o clima permitisse. Como o engenho de cana, a fazenda de café tornou-se um mundo em miniatura, procurando satisfazer as suas próprias necessidades. Nas fazendas, havia a casa do fazendeiro, estrebarias, carpintarias, oficinas, ferrarias, senzalas, terreiros para a secagem do gräo colhido, tulhas para armazena gem etcaso Entretanto, o modelo de organização empresarial diferia da cultura canavieira escravocrata, porque havia uma imprescindivel vinculação com os demais setores produtivos, e a mão-de-obra escrava era suplementada com a mão-de-obra imigrante, dos meados do século passado, e, após a abolição da escravatura, mudam também as relações de trabalho e também a forma de organizar a produção nas fazendas. Surge também um incipiente mercado interno e o imigrante não é só 
produtor de alimentos, mas também de bens de consumo manufaturados. Os imigrantes não vieram só substituir a mão-de-obra escrava, pois entraram cerca de 900 mil (subsidiados) entre 1887 e 1900, para 107 mil escravos existentes em São Paulo em 1887 (CASTRO, 1975).

A participação crescente da produção brasileira sobre a produção mundial do café, pode ser vista na tabela 01.

TABELA 01 - BRASIL - PARTICIPAÇĀO DA PRODUÇÃo CAFEEIRA NA PRODUÇĀO MUNDIAL

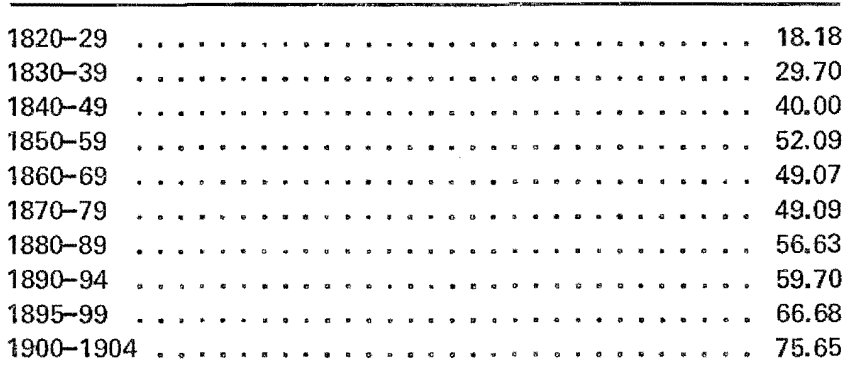

FONTE: Anuário Estatistico do Café

Ministério da Indústria e do Comércio//BC, 1980

Desde meados do século passado, o café ế uma importante fonte de divisas cambiais e influiu decisivamente na ocupação do território e na formação de uma aristo. cracia rural, ainda desvinculada dos reais problemas sociais como a preocupação com as condições de vida do trabalhador rural, qualidade da măo-de-obra ou da sua efetiva participação na sociedade. As relaçöes de trabalho evoluiram, do sistema escravocrata para o colonato, praticado intensamente com a crescente participaçäo da mão-de-obra imigrante na cafeicultura.

Entre 1890 e 1929, a produçầ cafeerra em Säo Paulo quintuplicou, tornando-se o princios produtor de care do pais, e o Brasil se tornou o principal someceder de cate para o mercado mundial, ate os anos 50.0 cal: representava em mëdin $50 \%$ da receira de divists do brasil, com picos como em 1924, quando a parioipacedo do cafe fol de 74\%, Esses dados assinalam a importannu da cafeiculura para a vida sócio-economica, principalmente quando se considera o seu papel como gerador de emprego e renda.

Nesse periodo e posteriormente até a década de 60 , no Paraná, o sistema de trabalho era o colonato, principalmente. Nesse sistema, o salário do trabalhador consistia em uma parte fixa, em função do número de cafeeiros tratados pela família, e, de uma parte variável, proporcional ao número de sacas de café por ele colhidas. Era ainda permitida à famillia do colono cultivar de forma intercalada aos pés de café, outras culturas como o feijão, arroz ou milho. A família era considerada como unidade, tanto para efeito de contrato como para remuneração, sendo que, o termo "colónia" adquire o significado de conjuntos residenciais próximas à sede rural, distribuldas em distintos planos, onde moravam as familias dos colonos (BASSANEZI, 1875).

Semina Ci. Soc./Hum., v. 15, n. 3, p. 270-279
Na virada do século, aproximadamente $80 \%$ da força de trabalho agrícola do Estado de São Paulo estava empregada na produção cafeeira sob o sistema de colonato (STOLCKE, 1986). Este sistema prevaleceu de 1880 até os anos 60 deste século, por cerca de 80 anos.

Nem sempre, o café alcançava um bom preço economicamente rentável no mercado internacional, e o sistema colonato dava flexibilidade aos fazendeiros para enfrentar as flutuações no preço do café, o que não seria possivel em sistema de trabalho assalariado. As relações de trabalho eram também marcadas por conflitos entre empregador e empregados. A greve era freqüente, entre 1913 e 1930, por melhores condições de pagamento ou contra limitações do direito de plantio de alimentos (Boletins do Departamento Estadual do Trabalho-SPs citados por STOLCKE, 1986).

O sistema "colonato" permitiu uma rápida ascensão social aos colonos, que, com a economia, conseguia adquirir terras em áreas de expansäo cafeeira, intermediada por corretores de empresas de colonizaçăo agrỉco. la, sobretudo após 1930, no Norte do Paraná - última fronteira agrícola cafeeira. Nessa época, ale̊m da facilidade na aquisição de lotes rurais, o preço da terra era ainda barato (NAKAGAWARA, 1981).

\section{5 - SISTEMAS DE TRABALHO}

Anteriormente, ao sistema colonato, outras for. mas foram praticadas, como a parceria, introduzida pelos fazendeiros paulistas desde 1847. Neste sistema, o fa. zendeiro financiava o transporte dos imigrantes de seu pals de origem até o porto de Santos e adiantava o custo do transporte de Santos até a fazenda, bem como os gêneros e instrumentos necessários aos imigrantes, ate que estes pudessem pagahlos com o produto de suas primeiras colheiras. Nas fazendas, os imigrantes cuhvavarn

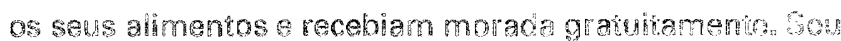

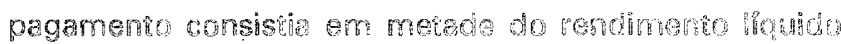

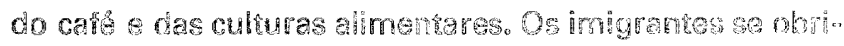

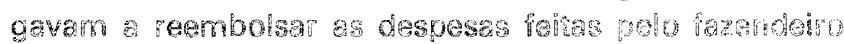
err seu benehicio com. pelo menos. melcde de seus go

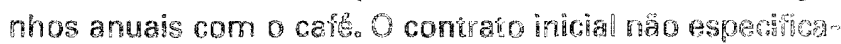
va sua durạăo, mas estabelecid o montante da duide a cargo do imigrante, devido aos custos de seu transporte outros adiantamentos. 0 trabalhador devia arcar com juros por qualquer montante pendente após 2 anos 0 que era o caso com outros adiantamentos após 1 ano, e só poderia deixar a fazenda após ter reembolsado suas dividas. Algumas famílias imigrantes conseguiam saldar suas dividas nos primeiros anos e se estabelecer por conta, mas geralmente a média se situava em torno de 4 anos. (STOLCKE, 1986).

O sistema de parceria foi gradativamente abandonado em São Paulo, após 1857, por um contrato de locaçảo serviços. Assim, ao invés de uma parcela do valor da produção, os trabalhadores recebiam um preço pré-estabelecido por café colhido, e o tamanho da roça de subsistência foi estabelecido em proporção aos pés de café tratados e/ou alugado por uma renda, numa tentati- 
va de desencorajar os imigrantes de desviarem trabalho para as culturas alimentares (MORAES, 1870, apud STOLCKE, 1986). E, os trabalhadores livres não mais

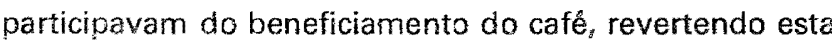
tarefa para os escravos, até a década de 1880, quando passou a ser executada por mão de obra assalariada.

Nas fazendas, havia tambêm um grupo de came radas geralmente homens solteiros ou jovens famllas que viviam na propriedade e recebiam um salårio mer 3al, realizancio tarefas diversas, dentro da fazenda. Havia tambem guarcas amados, on Gabngas. para garan que as ordens dos fozencleiros fossem executadas 100 LETT, 1908, apur STOLCKE, 1986). Apeser da mentaldade adicole emoresarial mais aberta dos fazendetos paulshas en relaço aos usineiros do Nordeste hevia ceramente fomas to coersobo inacoluvel. sh relatedes peios imigranes as passnas da intmidarle on atrayse de

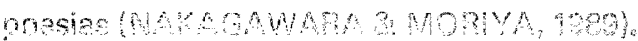

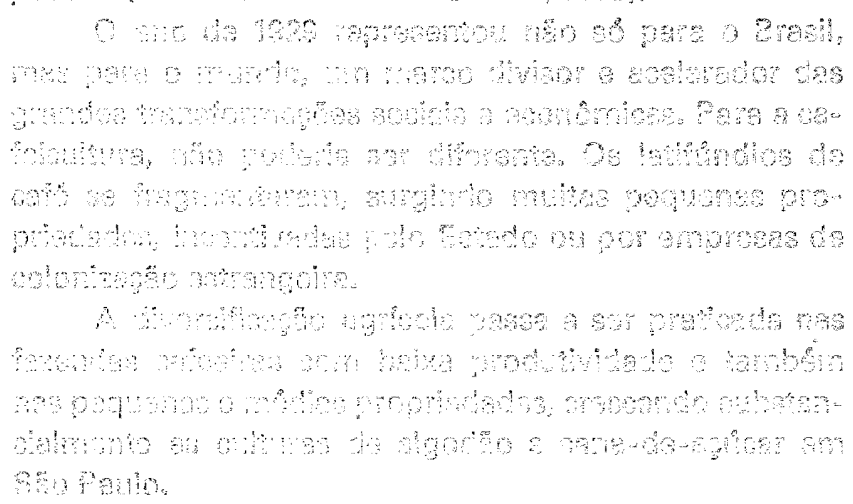

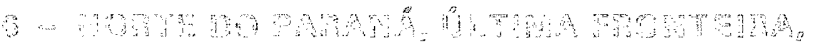

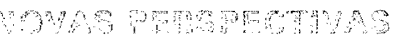

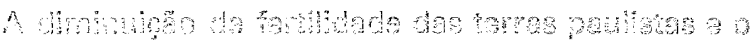

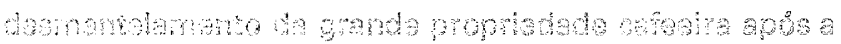

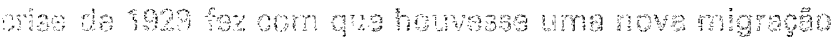

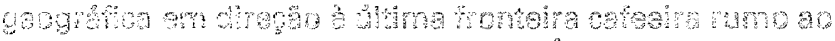

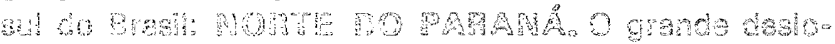

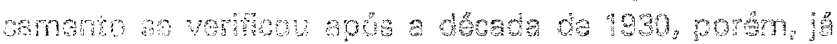

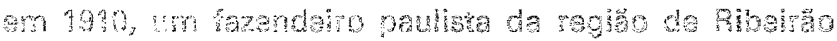

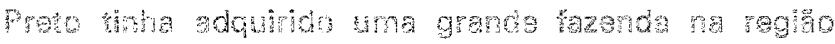

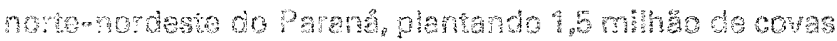

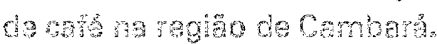

Arwameno a poulacho do Paran exp exmeda an carca de 9 minhes da pospos, sendo gue $70 \%$ dsese

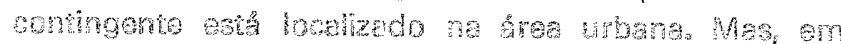

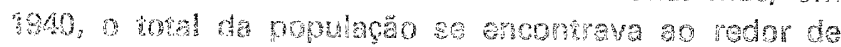

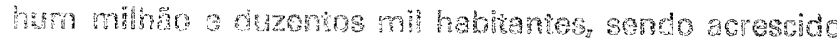

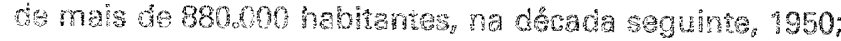

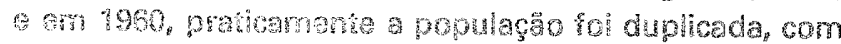
4264000 habinans 10 Estadn, mas apenas $30 \%$ da po pulaço se concentrave ra arge ubana. Nos decenios 40 50 e 50.60 , howve sm acrescino de $7.0 \%$ e $101,0 \%$ de populaçă respectivamente, decrescendo para $61,0 \%$ no dectrio 60-70. A partir da decada de 70,0 quadro se al. tera substancialmente, pois, no decênio $70-80$ a população cresce apenas $10,7 \%$, reflexo do intenso process? migratório, que sera referido posteriomente.

Semina Ci. Soc fHumo, vo 15, no. 3, p. 270-279
O grande afluxo migratório das décadas de 40 a 60 sempre se dirigia para a área rural, visando o trabalho na atividade cafeeira. Cerca de $75 \%$ da população paranaense se localizava na śrea rural, nos censos de 1940 e 1950 e, em 1960 , ainda havia $68 \%$ dos quais $73,8 \%$ da popula ção ocupada nos estabelecimentos agricolas se concentrava na Região Norte do Paran:

O grande impuiso na abertura dessa nova frente do expansão cafeeira fo dado por um empreendimento imobiliấlo Colonizador Inglês, que adquiriu junto ao go

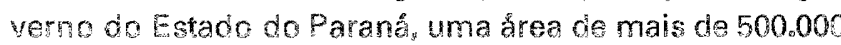
abueires oaulistas a iniciou nos tins de derada de 1920 um planejamento de ocupaça rural e urbana, baseado na divisă de lotes rurais em pequenas propriedades. dotando a regiäo de uma inira-estrutura bésica para 0 escramertio da rroduräb, arravas do assentamento do

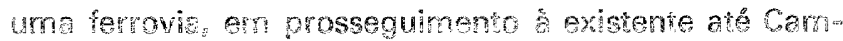

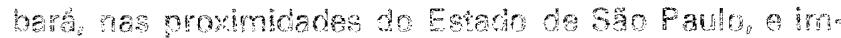

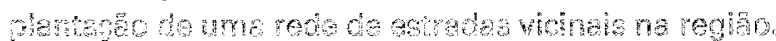

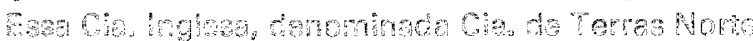

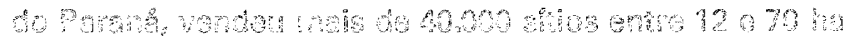

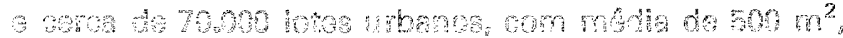

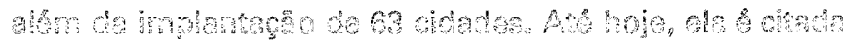

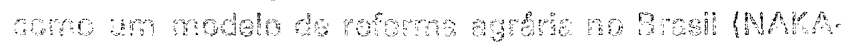
CMMAA, 1984

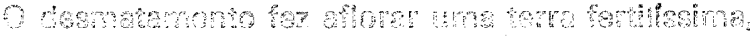

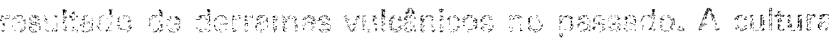

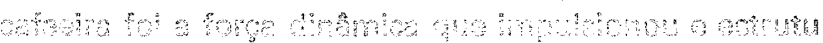

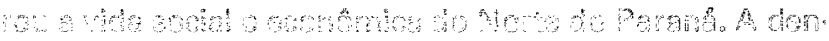

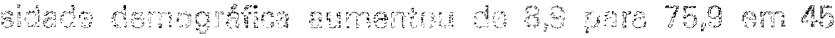

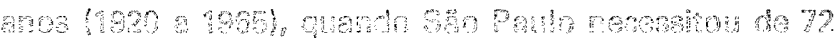

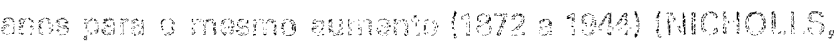

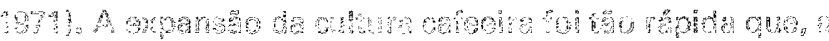

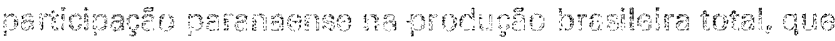

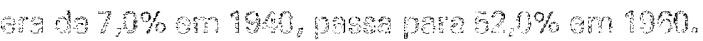

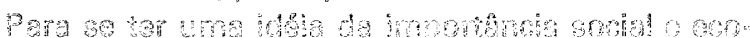

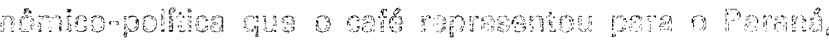

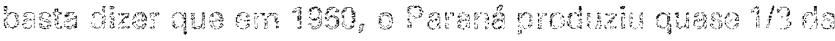

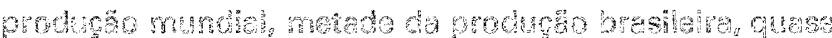

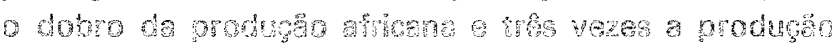
coloribiana.

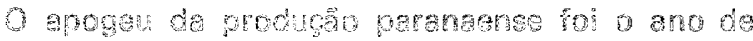

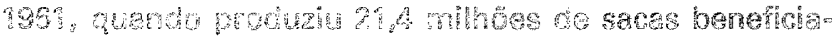

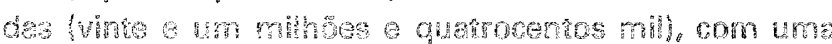

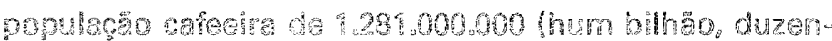

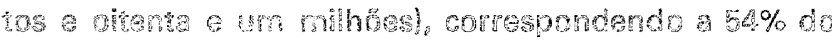
strasil.

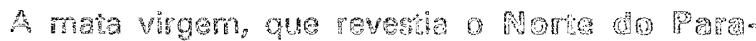

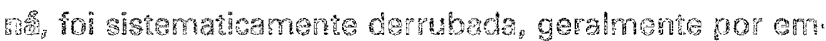
preineiros aspacializados contratabs para sse tim. $A$ derrubada ora segula de quemada, as primeiras

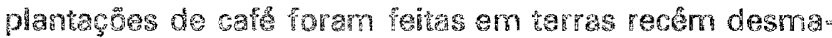
tadas, ao lado de milhares e mithares de madeiras de lei.

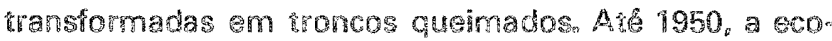
nomia quase ao nivel de subsistencia praticada no Para nag, passa a fazer parte da agricutura comercial ${ }_{2}$ influenciada pelo athuxo constante do população, engrossando a população rural e projetando a sua economia.

Alêm da "Cia. de Terras Norte do Paraná - CTNP" 
outras Cias. estrangeiras atuaram no Paraná, como a "Brasil TOKUSHOKU KAISHA - BRATAC", que fundou a Colônia Assal e a "NAMBEl TOSHI KABUSHIKI KAlSHA", que formou a Colônia Ural, ambas no Norte do Parană a cerca de $50 \mathrm{~km}$ de Londrina, sede da CTNP. Essas três Cias. venderam lotes rurais com $30 \%$ de entrada e o restante para ser pago parceladamente, em 4 ou 5 prestações anuais. Entre 1930 e 1938, os estrangeiros predominavam sobre os nacionais, como compradores de terras paranaenses. Nessa época, cerca de 33\% das propriedades paranaenses já pertenciam aos estrangeiros, principalmente lotes pequenos, de até 50 alqueires.

A formação da propriedade cafeeira paranaense foi diferente de São Paulo, que tinha se estruturado na grande fazenda monocultora. No Norte do Paraná, a grande maioria era constituída de pequenos lotes, cujos proprietários eram imigrantes e filhos de imigrantes, geralmente com experiência na cafeicultura em São Paulo, e também migrantes nacionais, procedentes de São Paulo, de Minas Gerais e de Estados do Nordeste.

Mesmo o colonato diferia do modelo paulista, pois a concentração de casas era menor e também o trabalho escravo já tinha se extinguido. Os colonos já não eram imigrantes, que, em sua maioria, já eram pequenos proprietários, comerciantes bem situados ou até profissionais liberais, desenvolvendo atividades nas áreas urbanas. Enfim, o colono imigrante tinha realizado o seu sonho de se tornar proprietário de "sítio", era "sitiante". desenvolvendo seu trabalho sob a base familiar, mas também com a ajuda de colonos nacionais e, em época de colheita havia a suplementação da mão-de-obra volante, por cerca de 60 a 90 dias, dependendo da área plantada com café. Havia também grandes propriedades no Norte do Parana", de 300,500 ou 1.000 alqueires, com dezenas de casas de colonos, mas eram "ilhas de exceção".

\section{7 - AGENTES DA PRODUÇÃO}

No Paraná, os agentes da produção envolvidos nas diferentes relações de trabalho na cafeicultura, são mais complexos e diferem do modelo paulista. O proprietário fundiário também é diferente. A gênese dessa diferenciação se situa no modelo de ocupação dessa nova fronteira agricola, embora assentado também na cafeicultura, na sua porção norte e oeste do Estado, em uma das regiōes de terras mais férteis do Brasil, denominada "terra ro$x \mathbf{a}^{\text {s" }}$.

Os trabalhadores nas propriedades cafeeiras do Paraná, em 1961, segundo pesquisa do Instituto Brasileiro do Café/OEA, estavam distribuldos em aproximadamente 290.000 familias, conforme Tabela 02.

Essas familias totalizavam 1.455 .253 pessoas trabalhando na cafeicultura, entre homens, mulheres $e$ crianças. O quadro demonstra a inferioridade dos proprietários, se comparada a colonos e parceiros. Segundo a condição de produtor, os parceiros eram responsåveis por 57.858 estabelecimentos com café, em 1970, decresSemina Ci. Soc./Hum., v. 15, n. 3, p. 270-279
TABELA 02 - TIPO DE TRABALHADOR NAS PROPRIEDADES CAFEEIRAS

\begin{tabular}{lcr}
\hline TIPO DE & $\begin{array}{c}\text { NUMERO DE } \\
\text { TRABALHADOR }\end{array}$ & \\
\hline 1- colonos & 84.357 & 29,7 \\
2- parceiros & 62.494 & 22,0 \\
3- proprietários e familias & 54.311 & 19,1 \\
4- diaristas & 34.950 & 12,3 \\
5- empreiteiros & 18.329 & 6,5 \\
6- administrador ou gerente & 11.805 & 4,2 \\
7 - outros & 17.676 & 6,2 \\
\hline TOTAL & 283.922 & 100,0 \\
\hline
\end{tabular}

FONTE: Instituto Brasileiro do Café/OEA, 1961.

cendo para 20.923 estabelecimentos, em 1980, isto é, uma redução de 36.935 estabelecimentos, evidenciando que os parceiros e mesmo os colonos não tinham acesso à terra, salvo algumas exceções. No periodo de $72 / 78$, o café gerou para o Paraná, cerca de $46 \%$ da exportação paranaense e $14,0 \%$ da arrecadaçäo estadual, demonstrando a sua importância como geradora de renda.

\section{8 - DESESTRUTURAÇÃo DA ATIVIDADE PRODUTIVA}

Nas décadas de 60 e 70 , ocorreram grandes transformações na economia paranaense, com a introdução de profundas mudanças de várias ordens. Quase toda a fronteira de expansão pioneira havia sido ocupada com o café, em direção leste/oeste, o solo das regiões onde esse produto tinha sido plantado anteriormente, já começava a mostrar um certo cansaço; as sucessivas ocorrências de geadas, moderadas ou fortes, de 1962, 1963, 1965 e 1969 influiram na diversificação agrícola e no aumento de pastagens; a implementação do Estatuto do Trabalhador Rural, em 1963, não respeitando as especificidades do trabalho rural heterogêneo e de naturezas diferentes no Brasil, introduz praticamente a mesma legislação trabaIhista urbana para o trabalho rural, visando dar maior proteção ao trabalhador, mas na prática, surtiu um efeito contrário, acelerando o processo de evasão da população rural, residente em colônias. Surgiram muitos advogados mal intensionados, que instigavam os trabalhadores a moverem açōes trabalhistas contra os proprietários, atravěs de intermediários denominados de "paqueiros". Os proprietários, em sua maioria, não tinham um controle contábil, nem tinham preocupações maiores com os seus trabalhadores, pois o sistema colonato era prática hå cerca de 80 anos.

Essa legislaçäo \& apontada como uma das causas da destruição do sistema "ascolonato" no Paraná. Por outro lado, no periodo de 1961 a 1971 , observa-se uma erradicaçäo de quase 500.000 .000 (quinhentos milhỏes) de pês de café, liberando uma ảrea de cerca de 730.000 .000 ha para as outras culturas pastagens ou renovaçäo de cafeeiros, estimulada pelo governo e somada å erradicação espontânea. 
Norte đo Paraná é a ültima fronteira sul possiei para o café, pois, as condições climáticas do Estado näo permitem a plantaçăo além do paraielo sul de $24^{\circ}$, apesar de ter sido plantado além desse limite, principalmente na década de 60 , ocupando arreas de baixa produvividade e regiões climáticas não recomendáveis.

Ss frequentes geadas que ocorreram no Norte do Paraná, prejudicaram muito os cafeeiros. Uma geada orte eleva os preços, porque demora de 1 a 3 anos para vortar a produzir, mas, há uma redução dråstica de renda para toda a população envolvida na produção, desde proprietários, trabalhadores ruiais, comerciantes aos secores de serviços.

A Ủitima geada, considerada severissima ocorreu am juiho de 1975, considerada a geada do século, quando foram danificados 915 milhöes de pès de cafe; outras cuituras também toram prejudicadas, como a queda de $25 \%$ da cana-de-açucar, de $80 \%$ da safra de trigo, além das pastagens inteiramente queimadas. Após a geada, foram erradicados apenas em um ano cerca de $211 \mathrm{mi}-$ hŏos de pés de cafe. Nessa ărea, dificilmente o café é replantadc. Foi destinada, em sua maioria, para a soja, pastagens e olitras lavouras temporárias anuais.

\section{3 - DIVERSIFICACAO E ROVAS RELAÇÕES DE PRODUCGAOE DE TRABALHO}

A introdução da soja no Paraná tem uma rảpida ascensăo após 9972 , propiciada pela tacilidade de mecanizaçăo, créditos bancários disponiveis para a acuisiçăo de tratores a implementos agricolas, tecnologia disponivel e conjuntura favorăvel a essa cultura, Alęrn disso, em um mesmo terreno, ha possibilidade de duas colheitas anuais, ce verão e de inverno. Assim, o trigo passa a ser cuitivado na mesma área da soja, durante o inverno, e o binômio soja/trigo passa a dominar as terras paranaen. ses. Em 1972, quando o catẻ estava praticamente recuperado da geada de 1969, ocorre nova geada, reduzindo a produça seguinte om mais de $45 \%$ e tambẻm nesse ano, surge a "ferrugem", nas tohas do café, cujo tratamento eleva o custo da produção.

Em 1973, o preço da soja passa de $\$ 42,00$ a saca para $\$ \$ 20,00$, contribuindo para mais erradicaçäo de cafeeiros, por ser também uma cultura de menor risco clinático, com rapidsz no retorno do investimento. No Bra. sil, de 1970 a 1980 , a área de soja passa de 1318,000 para 8.744 .000 hectares e hoje, produz cerca de 20 mithoues de soneladas. Es no Parana, mais surpreendente asse avanço, no mesmo perlodo, passando de 304,200 ha para 2.410.800 ha, em dez anos.

A introdução da soja significa tecnologia moderna, mecanização, pouca utilizaçäo de mão-de-obra e neces. sidade de ampliação de mais åreas para plantio para compensar os altos investimentos, com ráquinas e tra. tores para plantação, tratos culturais e colheita. Entim, um novo sistema agricola, uma nova mentalidade.

Todos esses fatos acima assinalados, provocaram uma violenta concentraçäo de terras a uma evasão da populaçăo paranaense. O processo de ocupação, estruSemina Ci. Soe fllum, v. 15, a. 3, p. 270-279 turaçăo, desestruturaçăo e nova reorganização agrária foi tăo rảpido e violento, que os fatos mal puderam ser registrados. Quando foi publicado o censo de $1980_{\text {z }}$ constatou-se que dos 310 municípios paranaenses, 170 apresentaram uma população menor do que a registrada em 3970, localizados principaimente no Norte do Estado (94\%) (NAKAGAWARA, 1981).

A maior perda demográfica foi na årea rural, com serca de 1.200 .000 habitantes rurais no periodo $70 / 80$.

Só no Norte do Paraná houve um decréscimo de serca de 75.000 estabelecimentos rurais, no intervalo de 5 anos, de 70 a 75 . Foram incorporados em sua maioria, a butros estabelecimentos vizinhos, pois, se a pequena propriedade foi ótima para o café, não o é para a cultura mecanizada do binômio soja/trigo e nem para a formação de pastos para a pecuåria.

Agora, so sojicultor e não o cafeicultor, aquele que dinamiza o capital rural, aquele que inova, que incorpora insumos modernos e, começa a surgir uma nova classe rural, constituida de profissionais liberais, como médicos, engenheiros, advogados, comerciantes bem situados e tambêm industriais. Ao lado dos cafeicultores tradicionais ou filhos de cafeicultores, às vezes, estes, são aqueles liberais que, não fazem da atividade cafeeira a sua principal renda, mas uma complementação ou uma forma de investir em terras rurais, pråtica muito comum na ascen. são social no Brasil.

Hoje, nas novas frentes de expansão do café, na re gião do cerrado em Minas Gerais, hả cafeicultores filhos de imigrantes que foram cafeicultores no Norie do Para. nă. As cooperativas e os programas de desenvolvimento do governo têm participado ativamente desse processo de conquista de novas fronteiras agricclas.

O colonato está definitivamente encerrado; muihas colônias foram fechadas ou destruldas. Algumas fazen. das mantêm familias nas aniigas colônias, porêm, sob ass: sua subsistencia ou como complemento como no sistema colonato, salvo raras exceçöes.

Geralmente, a cidade ô o local de residência do proprietário, reservando para fins de semana, uma visto. ria geral na propriedade, ou, quando a sua presença \& muito necessária na propriedade. 0 administrador é uma figura importante no desenvolvimento de suas atividades. Este não es um trabalhador braçai, mas um executor das ordens do proprietário e um mediador nas rela-

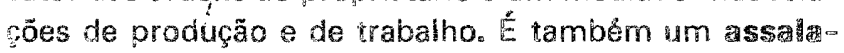
riado ${ }_{s}$ com ou sem comissāon

As propriedades cada vez mais capitalistas, procu. ram novas tecnologias, novos insumos e gura do profissional especializado em difundir tecnologia ou prestar assistência, geralmente na figura do agrôno. mo, veterinário ou zootecnista.

Estes putofissionais săo autônomos, executando ta. refas e recebendo por sipo de assistência, ou por comissão, dependendo muito do tipo de serviço prestado. Neste particular, as cooperativas têm sido eficientes, além do seu papel na comercialização dos produtos.

Com o advento da modernização tecnológica e mu- 
danças na estrutura produtiva, liberando centenas de milhares de familias das propriedades cafeeiras e não totalmente absorvidas em outras atividades, sejam rurais ou urbanas, surge uma massa de trabalhadores, sem um trabalho fixo, cuja atividade é, além de temporária, pouco remunerada.

\section{0 - BO̊IAS-FRIAS, PROBLEMA SOCIAL}

Com a decadência do colonato, e, consequentemente abandono da colônia, em direção a um núcleo próximo à propriedade ou para as cidades, os ex-colonos passam a efetuar tarefas não fixas, sendo transportados diariamente sobre um caminhão sem muita segurança, para a sua tarefa diária.

Nos povoados, distritos ou mesmo na periferia urbana de quase todos os municlpios norte e oeste paranaenses há pontos de recrutamento diário de trabalhadores denominados de "bóias-frias", geralmente mediados por um "gerenciador de mão-de-obra" chamado de "gato". Este, possui uma condução, geralmene em estado precário de conservação, e recebe um percentual da diária de cada bóia-fria. O pagamento geralmente é telixo semanalmente pelo proprietário a gato que repassa ao rabalhador a quantia jå descontada da sua comissão.

No Paraná, o trabaho por tarấ, executado por trabalhadores volantes sempre existit, cescle o inicio de sua expansăo e ocupação. Entretarto, a liberação de un grande contingente rural, procedente das propriedades cafeeiras, foi intensificada pós-60, prosseguindo na década seguinte, conforme exposto anteriomente. E, despro. vidos da sua casa, sem terra para plantar as culturas de sua subsistência, repentinamente se vê encurralado pela necessidade de sobrevivencia, e passa a vender a sua for ça de trabalho, perambulando diariamente solore um ca minhão, sem muitas vezes saber o local do seu trabalho ou a sua tarefa para o dia seguinte.

Evidentemente, nem todo colono se transformou em bóia-fria, como também, em proprietarios, porém, alguns pequenos proprietários rurais se transformaram em bóias-frias ou assalariados.

Há muitos bóias-frias que nunca foram colonos $e_{p}$ acredita-se que o grosso desse contingente ja esteja na $2^{\text {a }}$ ou $3^{\text {a }}$ geração de trabalhadores volantes no Parana. O ni. vel educacional é baixo e poucos conseguiram completar o curso primário (4 anos).

A sazonalidade das culturas paranaenses intlui também na sazonalidade da oferta de trabalho rural, $e$ segundo o Núcleo Regional da Secretaria da Agricuitura. a demanda média mensal para a safra $89 / 90$ estå estima. da em torno de 560.800 trabalhadores, para uma área de aproximadamente 6.316 .000 ha do Paraná. O período de novembro a dezembro apresenta as maiores demandas, coincidindo com os tratos culturais de verão. A partir de janeiro, a demanda média mensal se situa em torno de 350.000. O gráfico ao lado demonstra as oscilaçôes da demanda, indicando a instabilidade que caracteriza esse trabalho flutuante. Na realidade ${ }_{\beta}$ um sub-emprego dis. farçado.

Semina Ci.Soc./Hum, vo 15, n. 3, p. 270-279
A qualidade de vida decaiu violentamente, do coIonato para o assalariamento ou trabalho diário executado por bóias-frias.

PEASE (1973) demonstrou que existia uma diferença substancial a favor das rendas rurais no Brasil, em detrimento às rendas urbanas, que, se não forem $45 \%$ superiores à renda rural näo permite a compra do conjunto de Consumo Rural enriquecida principalmente com os cultivos alimentares, no colonato.

RIOS (1973) também escreveu que "apesar da disciplina rigorosa e da rotina do trabalho, devia ser este um dos mais bem pagos do mundo agrário brasileiro", referindo-se ao trabalho agrícola no café.

\section{1 - CONSIDERAÇÕES FINAIS}

A cafeicultura foi responsável pela transformação da vida agrária, urbana e industrial do Brasil. Do ponto de vista da expansão de frentes pioneiras e implantação de povoados $_{\varepsilon}$ cidades $_{\varepsilon}$ casas comerciais, ferrovias e empre sas de exportaçã $o_{*}$ talvez nenhum outro produto agricola possa competir com a sua importância social e econômi ca. O café é gerador de renda e trabalho, movimenta o comércio e da dinamismo a setor de servicos. Embora hoje represente cerca de $10,0 \%$ na exporação nacional. jâ participou com cerca de $70,0 \%$. Apesar de sua pouca par ticlpaçăo comercial gera anda una receita de mais de 2 bilhöes de dólares para o Brasil, anualmente.

O mercado cafeeiro transcende os limites nacionais cuia cotação é feita em bolsas de expressão internacional. como a de Nova York L Londres.

Ho no Brasil atualmente, cerca de 300.000 cafeiculo

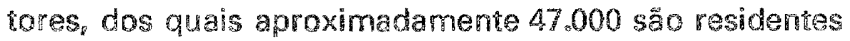
no Paraná. Há uma área de cerca de 2.8 milhões de her. tares plantados com mais de 4 bihöes de careeiros. Nos últimos anos, tem-se observado um acréscimo de äreas em novas regiobes do cerrado de Minas Gerais principal mente, como que retornando ao seu caminho anterior ao Paraná. Entretanto, hoje há muita techologia disponivel para a otimização da produção $o_{y}$ seja em termos de varie. dades para determinadas regiōes, em temos de espaçamento ideal para plantic, em termos de combate às pra. gas ou doenças, em termos de comercialização ou indus. trialização.

A cafeicultura foi responsåvel pela estruturação de uma extensa rede urbana, que e um imporante mencado consumidor para a atividade industrial que esse produto impulsionou, fazendo de São Paulo, por volta de 1920,0 centro industrial mais importante do Brasil, e em 1940, a maior aglomeração manufatureira da América Latina. Na ărea rural, propiciou uma aceleraçăo da economia mo. netária, estimulou novas relaçôes de trabalho além do trabalho escravo, mesmo antes da abolição, e, apesar de uma certa resistência dos fazendeiros, os imigrantes italianos a japoneses, inicialmente introduzidos como trabalhadores na cafeicultura, trouxeram novas contribuições ao Brasil ${ }_{i}$ do ponto de vista étnico e sócio-econômi co, melhorando os padrōes culturais então vigentes. 
Muitos fazendeiros se tornaram comerciantes, grandes empresários ou industriais, enfim, o café estimulou novas atividades sociais, polfticas e económicas.

Entretanto, paradoxalmente, há vários aspectos negativos relacionados a essa cultura. Queremos apontar duas, que merecem reflexão: uma, foi a indiscriminada destruição da mata que revestia as fronteiras de expansão por onde ele se ampliava como um mar verde e ondulante, desgastando o solo e depauperando o meioambiente; a outra, talvez seja o retrato mais triste da falta de conhecimento e incapacidade do homem em compreender a natureza da sua própria sociedade, e, consequentemente, trazendo soluções humanas e em tempo, para melhorar a qualidade de vida coletiva. Neste particular, cito os "bóias-frias" que ficam migrando de uma propriedade a outra, de uma cidade a outra, de um Estado a outro, trabalhando em várias atividades agricolas, como volantes ou flutuantes, ora na área rural, ora na urbana. O mercado urbano é incapaz de absorver ou atender a sazonalidade da oferta ou demanda da mão-deobra rural. O fim do colonato trouxe problemas de moradia, de alimentação e de descontinuidade na sua renda. As várias tentativas de melhorar as relações de trabalho, através de sindicatos não têm sido suficientes para meIhorar a sua qualidade de vida.

A agricultura cada vez mais capitalizada, os altos custos e os juros dos financiamentos agricolas, sem o necessário respaldo governamental em termos de política agricola, tem penalizado muito as relações sociais de produção e de trabalho no Brasil, em cujo contexto se situa a cafeicultura, e a questão dos trabalhadores volantes rurais.

Os trabalhadores rurais chamados de "bóias-frias", não possuem vínculo empregatício, porque são contratados geralmente por intermediários entre o proprietário rural e o trabalhador, recebendo uma diária insuficiente para sobreviver, porque a oferta de trabalho não é contínua, e, além de estar sujeito a oscilações climáticas, paga uma parcela do seu ganho ao "gato", seu intermediário.

Desde que haja uma "política voltada para o café", a médio e longo prazos, integrando a capacidade tecnológica já disponivel em entidades de pesquisa ou cooperativas, os atuais estudos já demonstram a viabilidade do café, pela sua produtividade e, para minimizar os riscos de geada, as recomendações indicam uma diversificação agrícola na propriedade, onde o café ocuparia cerca da terça parte, ao lado de outras culturas. Desta forma, o problema mão-de-obra rural poderia também ser resolvido em parte, uma vez que o café aínda não se viabilizou como uma cultura mecanizada e emprega muita mão-deobra, durante quase todo o ano, gerando renda e dinamizando vários setores de atividade.

Hoje, a cafeicultura não deve mais ser pensada como a mais rentável ou solucionadora de problemas, mas, como uma cultura que, respeitando o seu alcance tecnológico, é uma boa opção para o Paraná e Brasil.

\section{PRODUCAO DE SACAS DE CAFE ESTADOS: PARANA, SAO PAULO, MINAS GERAIS E ESPIRITO SANTO $1961 / 1987$}

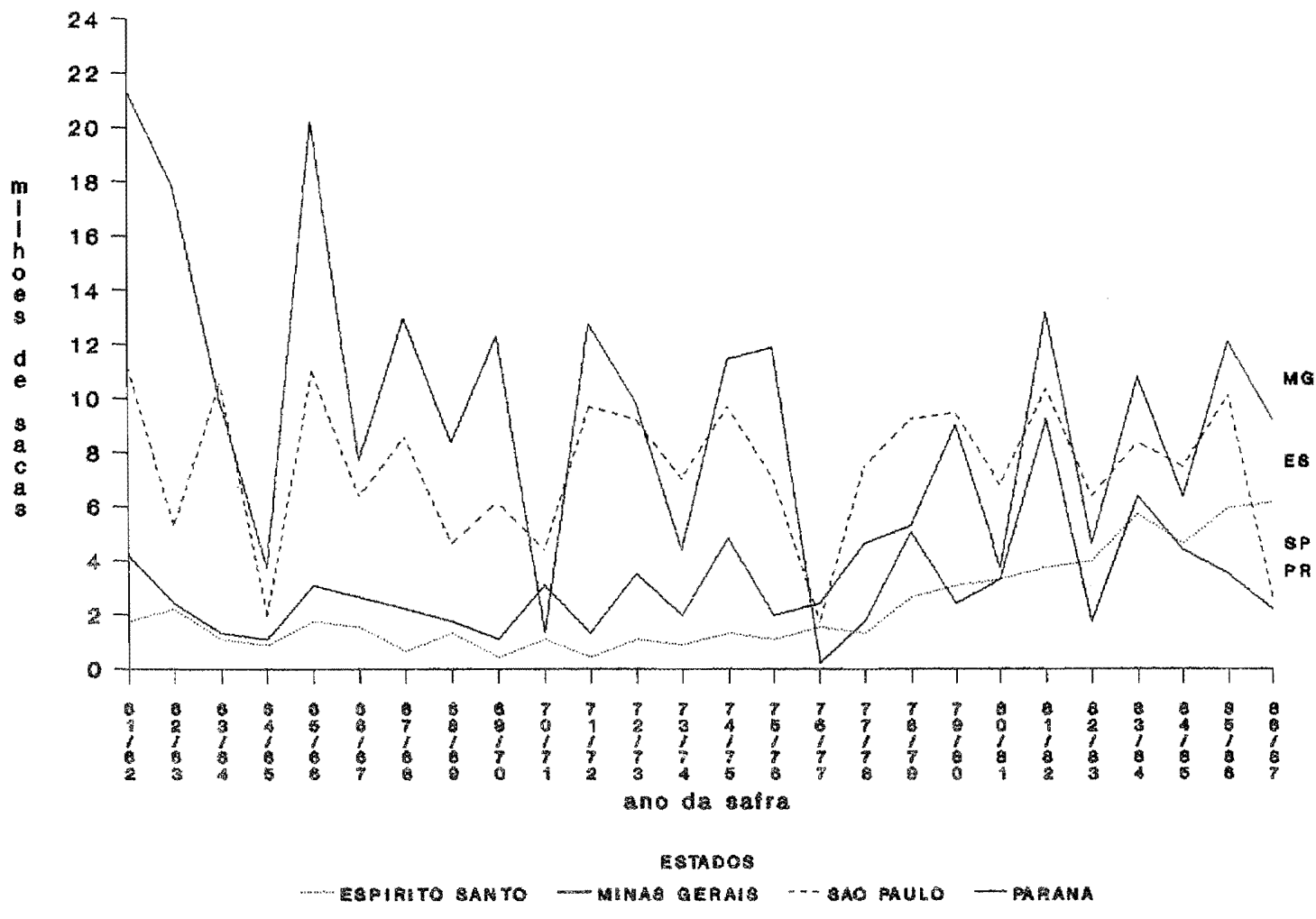

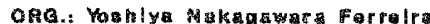

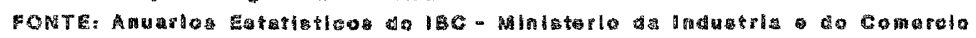




\section{ESTADO DO PARANA}

DEMANDA DA MAO DE OBRA NA AGRICULTURA

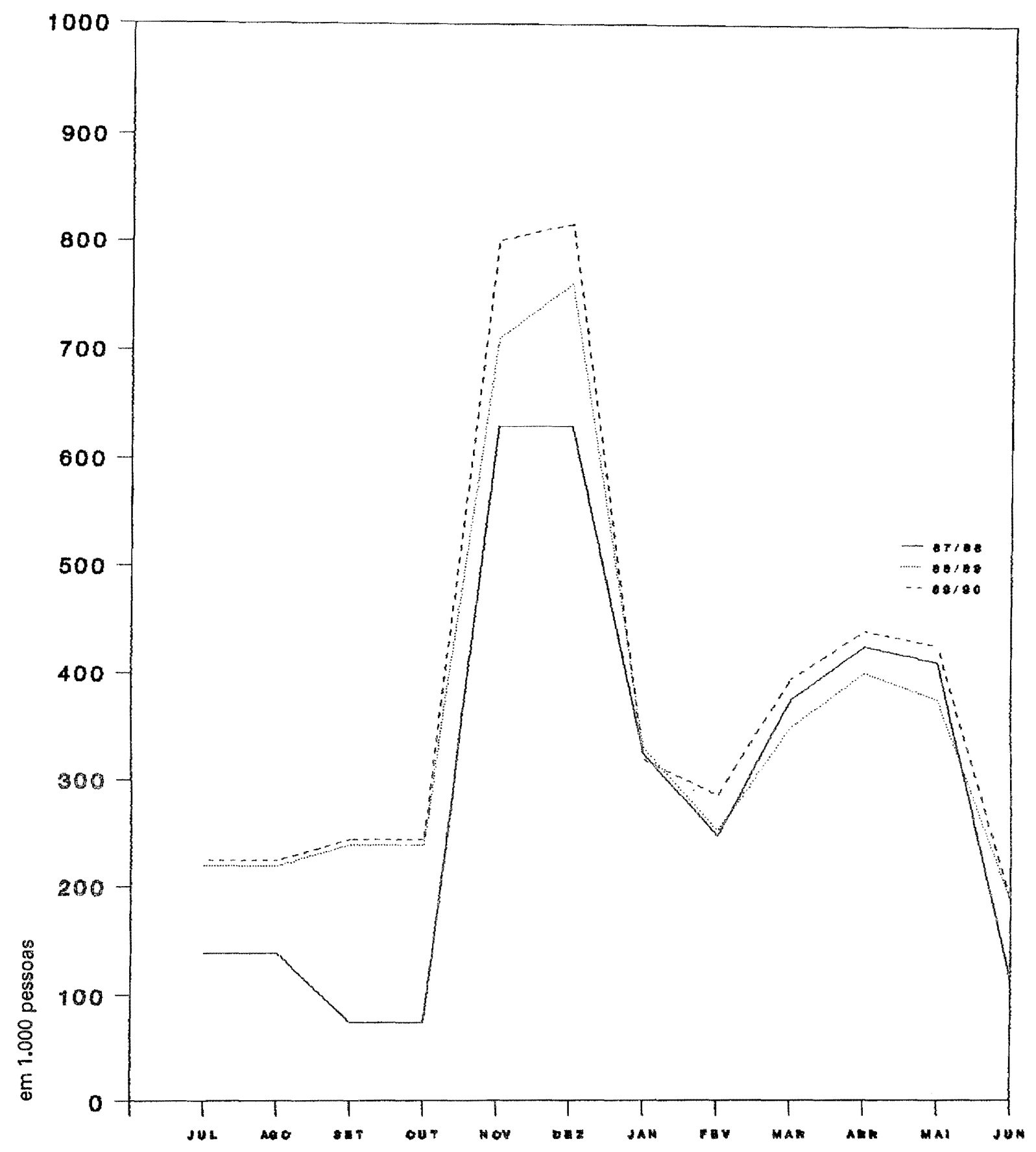

FONTE: 9EAB/DEAAL 
NAKAGAWARA, Y. Coffee, from "colonato" to rural proletarization. Semina: Ci. Soc./Hum., Londrina, v. 15, n. 3, p. 270-279, Sept. 1994.

ABSTRACT:This article shows a general view of the transformations occurred in the Brazilian coffee agriculture, centred in the states of São Paulo and Paraná. It presents a study on the different forms of social labour force and of production relations which are involved in the coffee agriculture. It sums up the social and economic role that coffee agriculture represented to Brazil as a whole.

KEY-WORDS: coffee; rural worker; frontier.

\section{REFERÊNCIAS BIBLIOGRÁFICAS}

BASSANEZI, M.C. Absorção e mobilidade da forca de trabalho numa propriedade rural paulista (1895-1930). In: CONGRESSO DE HISTÓRIA DE SÃO PAULO, 2., 1975 São Paulo. Anais... São Paulo, 1975, p. 20-28.

BOIANOVSKY, M.A. A expansão cafeeira e o movimento migratório (1880-1930). In: Instituto Brasileiro do Café. $O$ Café no Brasil. Rio de Janeiro: IBC, 1978. p. 115-149.

CANCIAN, N.A. Cafeicultura paranaense 1900-1970: estudo de conjunturas. São Paulo, 1977. 497p. Tese (Doutorado em História Sociall - USP.

CAR NEIRO FILHO, F. O planejamento da comercialização pelo produtor. Rio de Janeiro: Planejamento Cafeeiro, 1989. 98p.

NAKAGAWARA, Y. Questões agrárias e urbanas interdependência e subordinação - $O$ caso norte-paranaense. Terra e Cultura, Londrina, v. 1, n. 1 , p. 93-115, 1981.

O papel da Cia. de Terras Norte do Paraná no crescimento de Londrina e da Regiăo Norte-Paranaense. 1984. 4p. (Mimeo).

NAKA GA WARA, Y: MORIYA, N. Historia dos imigrantes japoneses através da poesia tanka. Londrina, [s.d.] Relatórios arquivados no Laboratório de Pesquisas Urbanas e Regionais do CCE/UEL.

NICHOLLS, W. A fronteira agricola na historia recente do Brasil. O Estado do Paraná, 1920-1965. Revista Paranaense de Desenvolvimento, Curitiba, n. 26, 1954.

PEASE, S. A diferenca entre as rendas urbanas e rurais no Brasil. In: Instituto Brasileiro do Cafe. Ensaios sobre café $e$ desenvolvimento económico. Rio de Janeiro: IBC, 1973. p. 535-548.

PESSAMILIO, H.M.R. A dinâmica social do café. In: - O cafê no Brasil. Rio de Janeiro: [s.1], 1978. p. 5-37.

PRADO JUNIOR, C. Fomação do Brasil Contemporâneo. 8. ed. São Paulo: Brasiliense, 1965. 398p.

RIOS, J.A. O café e a mão-de-obra agrícola. In: Instituto Brasileiro do Café. Ensaios sobre café e desenvolvimento económico. Rio de Janeíro: IBC, 1973. p. 3-27.

STOLCKE, V. Cafeicultura: Homens, Mulheres e Capital, (1850-1980). São Paulo: Brasiliense, 1986. 410p.

Recebido para publicação em 18/11/1993 